\title{
The Early Effect of Dextran Sodium Sulfate Administration on Carbachol-Induced Short-Circuit Current in Distal and Proximal Colon During Colitis Development
}

\author{
M. HOCK ${ }^{1,2}$, M. SOTÁK ${ }^{1}$, M. KMENT ${ }^{3}$, J. PÁCHA ${ }^{1,2}$ \\ ${ }^{1}$ Institute of Physiology, Academy of Sciences of the Czech Republic, Prague, Czech Republic, \\ ${ }^{2}$ Department of Physiology, Faculty of Science, Charles University, Prague, Czech Republic, \\ ${ }^{3}$ Institute of Clinical and Experimental Medicine, Prague, Czech Republic
}

Received May 4, 2011

Accepted June 28, 2011

On-line October 12, 2011

\begin{abstract}
Summary
Increased colonic $\mathrm{Cl}^{-}$secretion was supposed to be a causative factor of diarrhea in inflammatory bowel diseases. Surprisingly, hyporesponsiveness to $\mathrm{Cl}^{-}$secretagogues was later described in inflamed colon. Our aim was to evaluate changes in secretory responses to cholinergic agonist carbachol in distal and proximal colon during colitis development, regarding secretory activity of enteric nervous system (ENS) and prostaglandins. Increased responsiveness to carbachol was observed in both distal and proximal colon after 3 days of $2 \%$ dextran sodium sulfate (DSS) administration. It was measured in the presence of mucosal $\mathrm{Ba}^{2+}$ to emphasize $\mathrm{Cl}^{-}$secretion. The described increase was abolished by combined inhibitory effect of tetrodotoxin (TTX) and indomethacin. Indomethacin also significantly reduced TTXsensitive current. On the $7^{\text {th }}$ day of colitis development responsiveness to carbachol decreased in distal colon (compared to untreated mice), but did not change in proximal colon. TTXsensitive current did not change during colitis development, but indomethacin-sensitive current was significantly increased the $7^{\text {th }}$ day. Decreased and deformed current responses to serosal $\mathrm{Ba}^{2+}$ were observed during colitis induction, but only in proximal colon. We conclude that besides inhibitory effect of DSS on distal colon responsiveness, there is an early stimulatory effect that manifests in both distal and proximal colon.
\end{abstract}

\section{Key words}

Cholinergic • Ion transport • Colitis • Distal and proximal colon • Ussing chamber

\section{Corresponding author}

M. Hock, Department of Physiology, Faculty of Science, Charles University, Viničná 7, 12000 Prague 2, Czech Republic. Fax: +420221951772. E-mail: hock@natur.cuni.cz

\section{Introduction}

Ulcerative colitis (UC) and Crohn's disease are chronic inflammatory bowel diseases (IBD) in which the role of interactions between genetic, immunologic, microbial and environmental factors is expected, but exact etiology and pathogenesis still remain unclear (Kaser et al. 2010). A number of animal models mimicking different aspects of IBD were developed (Westbrook et al. 2010). In mice, an experimental colitis is probably the most commonly induced by oral administration of dextran sodium sulfate (DSS) (Okayasu et al. 1990). DSS induces acute colitis with symptomatic and histopathologic findings such as rectal bleeding, body weight loss, shortening of the colon, distortion of crypts, loss of goblet cells and infiltration of leukocytes. It is accompanied by increased transcription levels of inducible forms of cyclooxygenase (COX-2) and NO synthase (iNOS), and proinflammatory cytokines including tumor necrosis factor- $\alpha \quad(\mathrm{TNF}-\alpha)$ and

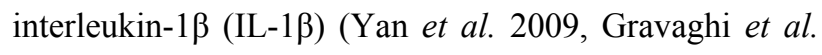
2011).

Inflammation strongly affects the intestine including its motility, activity of gut nervous system and intestinal transport. It is associated with increased ion and 
water secretion, resulting in a diarrhea, a typical lifecomplicating symptom of IBD that affects virtually $100 \%$ of UC patients. The overstimulation of colonic $\mathrm{Cl}^{-}$ secretion followed by water secretion was suspected as a causative factor of diarrhea because secretory effects of proinflammatory mediators TNF- $\alpha$, IL-1 $\beta$ or prostaglandins were reported in vitro (Bode et al. 1998). However, studies of the intestine in IBD patients and different animal models revealed a reduced sensitivity to secretagogues, including mediators of enteric nervous system (ENS), prostaglandins and cytokines (MartínezAugustin et al. 2009).

An altered response of inflamed colon to secretory stimuli was demonstrated also for ENS mediator acetylcholine, respectively its stable analog carbachol (Diaz-Granados et al. 2000). Carbachol triggers $\mathrm{Cl}^{-}$secretion in colonocytes by activation of $\mathrm{Ca}^{2+}$ dependent pathway via muscarinic receptors (Haberberger et al. 2006, Hirota and McKay 2006a). An increase in concentration of intracellular $\mathrm{Ca}^{2+}$ results in basolateral $\mathrm{K}^{+}$channel opening $\left(\mathrm{K}_{\mathrm{Ca}} 3.1\right)$ and membrane hyperpolarization, which drives the apical $\mathrm{Cl}^{-}$efflux (Flores et al. 2007, Matos et al. 2007). The extent of carbachol-sensitive $\mathrm{Cl}^{-}$secretion depends on (i) the resting membrane potential (respectively, the difference between membrane potentials before and after $\mathrm{K}^{+}$channels opening), (ii) the intracellular concentration of $\mathrm{Cl}^{-}$, which is transported into the cell by $\mathrm{Na}^{+}-\mathrm{K}^{+}-2 \mathrm{Cl}^{-}$ cotransporter isoform 1 (NKCC1) localized on the basolateral membrane and (iii) the activity of cystic fibrosis transmembrane conductance regulator (CFTR), a cAMP-regulated $\mathrm{Cl}^{-}\left(\mathrm{HCO}_{3}{ }^{-}\right)$ion channel expressed on the apical membrane (Hirota and McKay 2006b). To function properly, the $\mathrm{Ca}^{2+}$-dependent signaling pathway seems to require a baseline level of cAMP because it stimulates $\mathrm{NKCCl}$ and $\mathrm{Na}^{+} / \mathrm{K}^{+}$ATPase activities and opens CFTR channel (Barret and Keely 2000). The most important modulators of cAMP levels in enterocytes are likely the VIPergic part of ENS tonus and prostaglandins (Kunzelmann and Mall 2002).

Studies of colonic secretion during acute colitis focus almost exclusively on an inflamed tissue several days after DSS insult (Asfaha et al. 1999, Diaz-Granados et al. 2000, Sayer et al. 2002, Green et al. 2004, PerezNavarro et al. 2005), but changes of intestinal secretion during the development of acute colitis have not been investigated. Nevertheless, DSS administration may influence intestinal secretion much earlier than considered before. Johansson et al. (2010) demonstrated that $3 \%$ DSS can decrease thickness of protective mucus layer within $15 \mathrm{~min}$ and increase permeability of mucus layer to bacteria already after 12 hours. Therefore, our aim was to characterize the effect of DSS administration on carbachol-induced currents in distal and proximal colon during the colitis development, regarding secretory activity of ENS and prostaglandins.

\section{Methods}

Animals

Male BALB/c mice (10-14 weeks old, Institute of Physiology, Czech Academy of Sciences, Prague) were housed at controlled temperature $\left(21^{\circ} \mathrm{C}\right)$ and photoperiod (12:12-hr light-dark cycle) with standard mouse chow and tap water ad libitum (according to guidelines of the European Community). Mice were allowed to acclimate for at least a week before experiments or induction of colitis. The study was approved by the Institutional Animal Care Commitee.

\section{Colitis induction}

Mice were given $2 \%(\mathrm{w} / \mathrm{v})$ DSS (MW $40 \mathrm{kDa}$; Affymetrix UK Ltd., United Kingdom) in drinking water for 7 days. Untreated mice (day 0), mice during DSS drinking (day 3, 5 and 7) and mice 4 weeks after DSS removal (day 35) were killed by decapitation under ether anesthesia. The entire colon was excised, rinsed to remove its content, opened along the mesenteric border and used for further experiments, or immediately frozen in liquid nitrogen for RT-PCR.

\section{Colitis assessment and histological evaluation}

The severity of colitis was assessed on days 0,3 , 5, 7 and 35 using macroscopic markers (rectal bleeding, body weight and colon length), the transcript levels of proinflammatory markers TNF- $\alpha$, IL- $1 \beta$ and COX-2 (constitutive COX-1 measured as well) and histological scoring. The parts of distal colon corresponding to segments utilized for electrophysiological and mRNA analysis were fixed in $8 \%$ formaldehyde, paraffin embedded, sectioned and stained with hematoxylin and eosin. Blind sections were scored by a pathologist (activity of inflammation, 0-3; number and size of lymphoid follicles, 0-3; and crypt distortion extent, 0-3) and the total score was calculated for each colon sample.

\section{Ussing chamber experiments}

Whole-thickness segments of distal and 
proximal colon were mounted in a modified Ussing chambers $\left(0.096 \mathrm{~cm}^{2}\right.$ opening $)$. The tissue was bathed on both sides in Krebs-Ringer solution (composition in $\mathrm{mM}: 140.5 \mathrm{Na}^{+}, 5.4 \mathrm{~K}^{+}, 1.2 \mathrm{Ca}^{2+}, 1.2 \mathrm{Mg}^{2+}, 119 \mathrm{Cl}^{-}$, $21 \mathrm{HCO}_{3}^{-}, 0.6 \mathrm{H}_{2} \mathrm{PO}_{4}^{-}, 2.4 \mathrm{HPO}_{4}{ }^{2-}, 10$ D-mannitol, $10 \mathrm{D}$-glucose, $2.5 \mathrm{~L}$-glutamine, $0.5 \beta$-hydroxybutyrate) gassed with carbogen $\left(95 \% \mathrm{O}_{2}+5 \% \mathrm{CO}_{2}\right)$ and kept at $37{ }^{\circ} \mathrm{C}$. After an equilibration period of $30 \mathrm{~min}(20 \mathrm{~min}$ in open circuit mode and $10 \mathrm{~min}$ in voltage-clamp mode), the response to serosal carbachol $\left(10^{-4} \mathrm{M}\right)$, serosal TTX $\left(10^{-6} \mathrm{M}\right)$, serosal indomethacin $\left(5.10^{-5} \mathrm{M}\right)$, and mucosal and serosal $\mathrm{Ba}^{2+}\left(5.10^{-3} \mathrm{M}\right)$ was recorded by a computer-controlled voltage clamp (Müssler Scientific Instruments, Aachen, Germany). Net active ion transport across the epithelium was measured as a short-circuit current (SCC; expressed as $\mu \mathrm{A} . \mathrm{cm}^{-2}$ ) in voltage-clamp mode. In experiments, where a combination of several drugs was used, they were added sequentially in 5-min intervals except of indomethacin, where 10-min interval was used because of a slower colonic tissue response to this drug. In addition to SCC, the potential difference and tissue resistance were recorded at sampling frequency $1 \mathrm{~Hz}$, the data stored and further processed. To avoid underestimating electrogenic $\mathrm{Na}^{+}$absorption via epithelial $\mathrm{Na}^{+}$channel $(\mathrm{ENaC})$, responses to amiloride $\left(10^{-5} \mathrm{M}\right)$ were measured on untreated distal and proximal colon, during and after DSS administration. No amiloride-sensitive current was detected (data not shown).

$R N A$ extraction, reverse transcription and quantitative real-time $P C R$

Total RNA was isolated from whole-thickness segments of distal and proximal colon using GenElute Total Mammalian RNA Miniprep Kit (Sigma-Aldrich, St. Louis, MO, USA). The RNA concentration was estimated spectrophotometrically at $260 \mathrm{~nm}$ using Nanodrop ND-1000 (NanoDrop Technologies, Wilmington, DE, USA). The first strand cDNA was synthesized using $1 \mu \mathrm{g}$ of RNA with random hexamers $(0.5 \mu \mathrm{g})$ in a reaction volume of $15 \mu \mathrm{l}$ using Im-Prom II Reverse Transcription System (Promega, Madison, WI, USA) according to manufacturer's protocol. To detect relative abundance of mRNA of particular genes, real-time PCR was performed using ABI Prism 7000 Sequence Detection System (Applied Biosystems, Foster City, CA, USA) in $20 \mu \mathrm{l}$ reaction volume. Each reaction contained Gene Expression Master Mix, gene-specific pre-made
FAM-labeled TaqMan probes and primers or VIC-labeled TaqMan for normalization gene (TaqMan Gene Expression Assays, Applied Biosystems) and $1 \mu 1$ of 4 times diluted cDNA. Following thermal conditions were applied: $2 \mathrm{~min}$ at $50{ }^{\circ} \mathrm{C}$, initial denaturation step for 10 min at $95^{\circ} \mathrm{C}$ followed by 45 cycles of denaturation for $15 \mathrm{~s}$ at $95^{\circ} \mathrm{C}$ and annealing and elongation for $1 \mathrm{~min}$ at $60{ }^{\circ} \mathrm{C}$. Fluorescence acquisition occurred at the end of each elongation step. The assays IDs and accession numbers (NCBI RefSeq) of related genes are as follows: TNF- $\alpha$ (Mm00443258_m1, NM_013693.2), IL-1 $\beta$ (Mm00434228_m1, NM_008361.3), COX-1 (Mm00477214_m1, NM_008969.3), COX-2 (Mm00478374_m1, NM_011198.3). Relative quantification was assessed from obtained $\mathrm{Ct}$ values (7000 System SDS Software, Applied Biosystems) using standard curve method. The data were normalized to 18S rRNA (4308329, NR_003278). Ct values of the normalization gene were consistent and did not change across experimental groups. To get a clear demonstration, the mean value of distal colon controls was arbitrarily set at 1 for each gene.

\section{Statistical analysis}

Non-electrophysiological data were compared by one-way analysis of variance (ANOVA) combined with Dunnet's post hoc test and the values are reported as means \pm S.E.M. Baseline SCC and tissue resistance were compared by Student's t-test or one-way ANOVA combined with Dunnet's post hoc. Results are expressed as means \pm S.E.M. However, induced current responses were not compared by standard method, i.e. maximal deviations from baseline SCC compared by Student's t-test or one-way ANOVA. A new approach for comparison of two responses was used, taking into account not only the maximal deviations, but also differences in the shape of the responses. This approach was chosen since it was impossible, using the standard method, to statistically distinguish some responses that were evidently different in shape, but had similar maximal deviations. For example, this was the case for comparison of carbachol-induced currents (in the presence of mucosal $\mathrm{Ba}^{2+}$ ) in distal and proximal colon of untreated mice (Results; Fig. 3). Because of that new method, SCC records were further processed before statistical evaluation. All 5-min parts of record (or 10-min for indomethacin) corresponding to the specific drug combination were extracted from original records and aligned on an average curve. Each point of the 
average curve represents mean \pm S.E.M. Only 270 s of aligned records (or $540 \mathrm{~s}$ for indomethacin) that corresponded to the specific drug combination were used for subsequent analysis. Maximal or minimal deviation from baseline SCC that is used in the text where graphical representation is not possible, is presented as means \pm S.E.M. Notation $\Delta \mathrm{SCC}_{270}$ (or $\triangle \mathrm{SCC}_{540}$ for indomethacin) is used to emphasize that maximum or minimum value was found on $270 \mathrm{~s}$ long (or $540 \mathrm{~s}$ for indomethacin) average curve. A repeated measures ANOVA was used to statistically compare two average curves. Area under the curve was used as a dependent variable for all comparisons. Strictly speaking, the area under each aligned corresponding record was parted into 9 areas (or 18 areas for indomethacin), one area corresponding to $30 \mathrm{~s}$. Each area was calculated as a sum of charges transferred per s. Number of areas per curve represents a compromise between number of parameters describing a curve and accuracy of the method. The described procedure was repeated with all drug combinations applied to distal or proximal colon. The interaction between different drug combinations (in distal and proximal colon) and 9 (or 18) parameters describing area changing in time was tested. Because sphericity assumption (Maulchy 1940) was violated, probably due to the character of the data, Hyun-Feldt correction for violations of sphericity was applied when significance calculated. In all comparisons $\mathrm{p} \leq 0.05$ was accepted as a statistically significant difference.

\section{Results}

\section{Development of DSS-induced colitis}

After $2 \%(\mathrm{w} / \mathrm{v})$ DSS administration for 7 days a majority of mice developed severe colitis. The histological evidence of colitis is given in Figure 1. The mice lost $20 \%$ of their body weight $(n=16, p<0.001)$ and their colons shortened from $9.3 \pm 0.5 \mathrm{~cm}(\mathrm{n}=4)$ to $6.3 \pm 0.2 \mathrm{~cm}(\mathrm{n}=16 ; \mathrm{p}<0.001)$. Traces of rectal bleeding and watery stool were found around rectum. These symptoms were accompanied by significantly increased transcription levels of TNF- $\alpha$, IL- $1 \beta$ and COX- 2 in distal colon and, with exception of TNF- $\alpha$, also in proximal colon; although not so markedly (Fig. 2). Surprisingly, COX-1 transcription level was also increased in both distal and proximal colon (Fig. 2). Transepithelial resistance, which is often used as an electrophysiological marker of epithelial disruption, did not decrease in either distal or proximal colon during colitis development. Contrarily, it was significantly increased compared to untreated tissue on the $3^{\text {rd }}$ and the $5^{\text {th }}$ day of DSS administration, but only in the distal colon (day 0: $50.4 \pm 1.0 \quad \Omega . \mathrm{cm}^{2}, \quad \mathrm{n}=97$; day 3: 61.8 $2.1 \Omega . \mathrm{cm}^{2}, \mathrm{n}=34, \mathrm{p}<0.001$; day 5: $57.4 \pm 1.6 \Omega . \mathrm{cm}^{2}$, $\mathrm{n}=31, \mathrm{p}<0.01$ ). The untreated distal and proximal colon did not differ in their transepithelial resistance.

Tonic activity of ENS and prostaglandins during colitis development

In untreated mice, the baseline SCC was significantly higher in proximal colon compared to distal colon (PC: 94.0 $\pm 2.9 \mu \mathrm{A} . \mathrm{cm}^{-2}, \mathrm{n}=103 ; \mathrm{DC}$ : $\left.76.4 \pm 2.7 \mu \mathrm{A} . \mathrm{cm}^{-2}, \mathrm{n}=97, \mathrm{p}<0.001\right)$. Tonus of ENS, measured as TTX-sensitive current, was similar in distal $\left(\Delta \mathrm{SCC}_{270}=-19.1 \pm 2.6 \mu \mathrm{A} \cdot \mathrm{cm}^{-2}, \mathrm{n}=30\right)$ and proximal colon $\left(\Delta \mathrm{SCC}_{270}=-20.6 \pm 2.4 \mu \mathrm{A} \cdot \mathrm{cm}^{-2}, \mathrm{n}=29\right)$. Likewise, tonic activity of COX-derived mediators, inhibited by indomethacin, was not significantly different in distal $\left(\Delta \mathrm{SCC}_{540}=-9.6 \pm 2.7 \mu \mathrm{A} \cdot \mathrm{cm}^{-2}, \mathrm{n}=16\right)$ and proximal colon $\left(\Delta \mathrm{SCC}_{540}=-8.2 \pm 1.6 \mu \mathrm{A} . \mathrm{cm}^{-2}, \mathrm{n}=16\right)$. During DSS administration, baseline SCC decreased only the $7^{\text {th }}$ day of colitis development and only in distal colon (day 0: $76.4 \pm 2.7 \mu \mathrm{A} . \mathrm{cm}^{-2}, \mathrm{n}=97$ vs. day $7: 63.5 \pm 3.8 \mu \mathrm{A} . \mathrm{cm}^{-2}$, $\mathrm{n}=34, \mathrm{p}=0.05$ ). Nevertheless, tonic activity of ENS was stable in both distal and proximal colon. Tonic secretory activity mediated by prostaglandins did not change until the $7^{\text {th }}$ day of colitis development. In DSS treated mice, SCC response to indomethacin approximately doubled compared to untreated tissue in both distal $(\mathrm{p}<0.05)$ and proximal colon $(\mathrm{p}<0.001)$ (Fig. 3). An interaction between TTX and indomethacin was present throughout all time points measured in distal and proximal colon. Indomethacin reduced TTX-sensitive currents of distal and proximal colon similarly in untreated mice, during DSS administration and 4 weeks after DSS administration. The strongest interaction were found the $7^{\text {th }}$ day of DSS administration (Fig. 3). In the presence of indomethacin TTX-sensitive current was significantly reduced in both distal $(\mathrm{p}<0.01)$ and proximal colon $(\mathrm{p}<0.05)$, but concurrently, TTX reduced indomethacinsensitive current in both distal $(\mathrm{p}<0.05)$ and proximal colon $(p<0.001)$. In contrast to the inhibitory effect of indomethacin on TTX-sensitive currents, TTX reduced indomethacin-sensitive currents only the mentioned $7^{\text {th }}$ day of colitis development. 


\begin{tabular}{|l|ccc|}
\hline day 0 & day 3 & day 5 & day 7 \\
\cline { 2 - 4 }
\end{tabular}
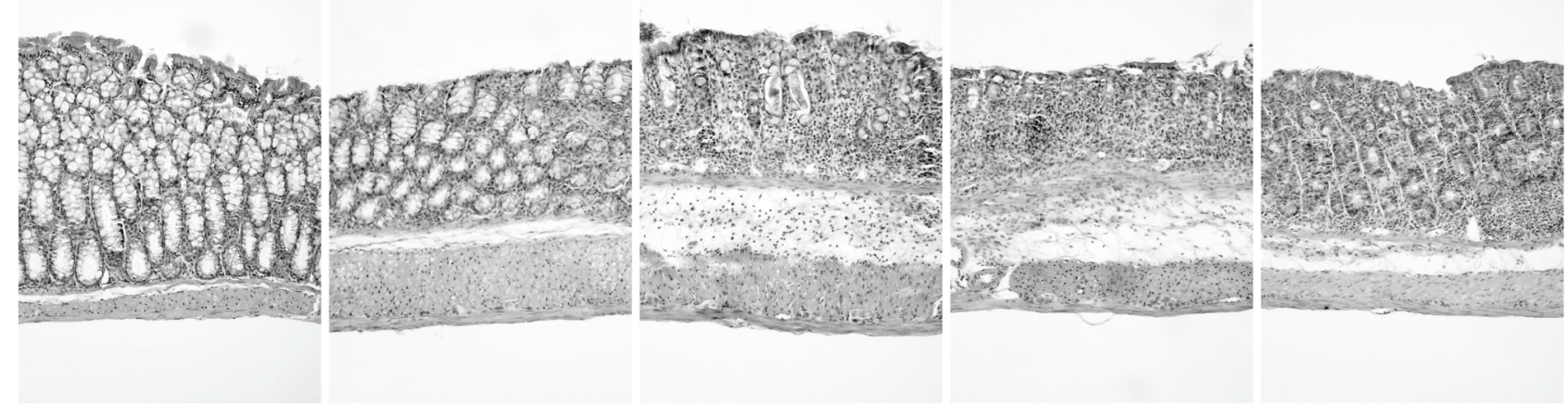

Fig. 1. Histological evidence of colitis. Samples of distal colon were taken before (day 0), during (day 3, 5 and 7) and 4 weeks after administration of $2 \%$ DSS (day 35). Tissue was stained with hematoxylin and eosin, samples were scored as mentioned in Methods and effect of DSS tested by ANOVA followed by Dunnet's post hoc test. Significant effect of DSS was found the $7^{\text {th }}$ day of DSS administration and 4 weeks after DSS insult (histological score - day 0: $1.5 \pm 0.25 ;$ day 7: $7.0 \pm 0.6, p<0.001 ;$ day 35: 5.0 $\pm 1.5, p<0.05 ; n=4$ ).
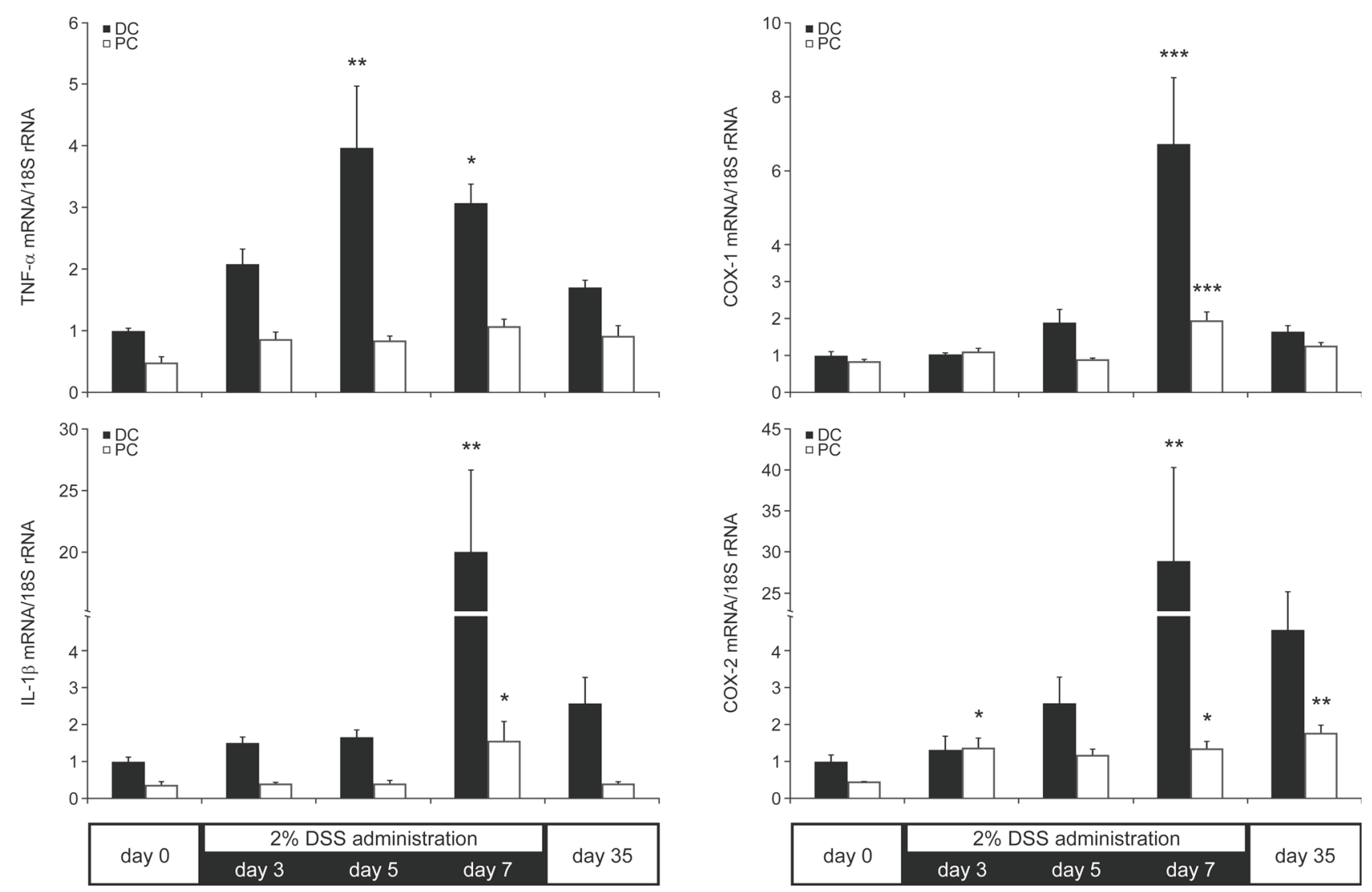

Fig. 2. Molecular markers of inflammation. Transcription levels of TNF-a, IL-1 $\beta$, COX-1 and COX-2 were measured before (day 0 ), during (day 3, 5 and 7) and 4 weeks after administration of $2 \%$ DSS (day 35) in distal (black columns) and proximal colon (white columns). The levels of gene transcription in distal colon corresponding to day 0 were arbitrarily set to 1 for each gene. Significance tested by ANOVA followed by Dunnet's post hoc test (compared to day 0 : * $p<0.05, * * p<0.01$ and $* * * p<0.001 ; n=4-6$ ). 


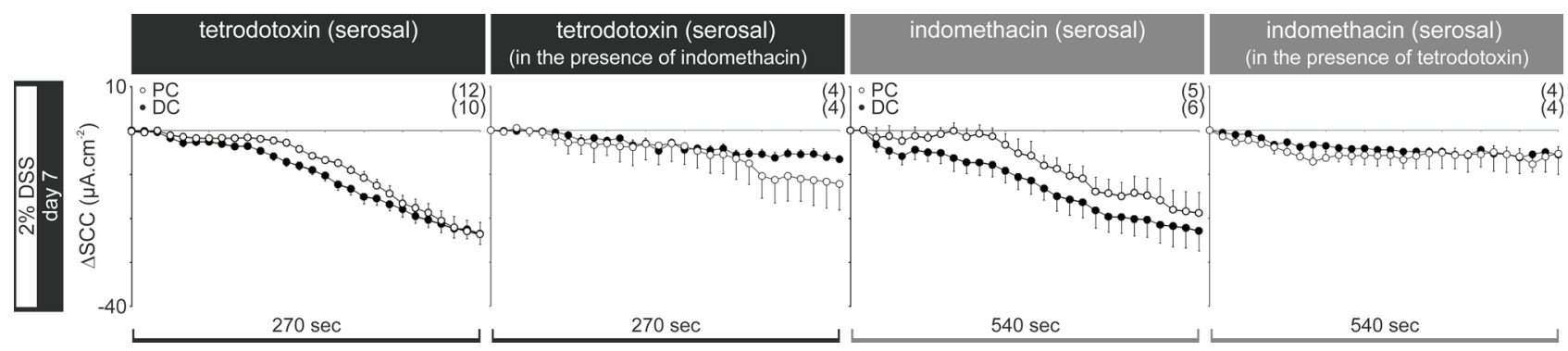

Fig. 3. Interaction between enteric nervous system (ENS) and prostaglandins. Responses of distal (DC; $\bullet$ ) and proximal colon (PC; $\circ)$ to tetrodotoxin $\left(T \mathrm{TX} ; 10^{-6} \mathrm{M}\right)$ and indomethacin $\left(5.10^{-5} \mathrm{M}\right)$ the $7^{\text {th }}$ day of $2 \%$ DSS administration are displayed. TTX-sensitive current represents tonus of ENS and indomethacin was used to inhibit synthesis of COX-derived mediators. The average curve represents 270 sec tracing (or $540 \mathrm{sec}$ for indomethacin), but only each $10^{\text {th }}$ point (or $20^{\text {th }}$ for indomethacin) is displayed for simplicity. TTX-sensitive current was significantly lower in the presence of indomethacin in both distal $(p<0.01)$ and proximal colon $(p<0.05)$. Similarly, indomethacin-sensitive current was reduced by TTX in distal $(p<0.05)$ and proximal colon $(p<0.001)$. The number of measured animals is in parentheses.

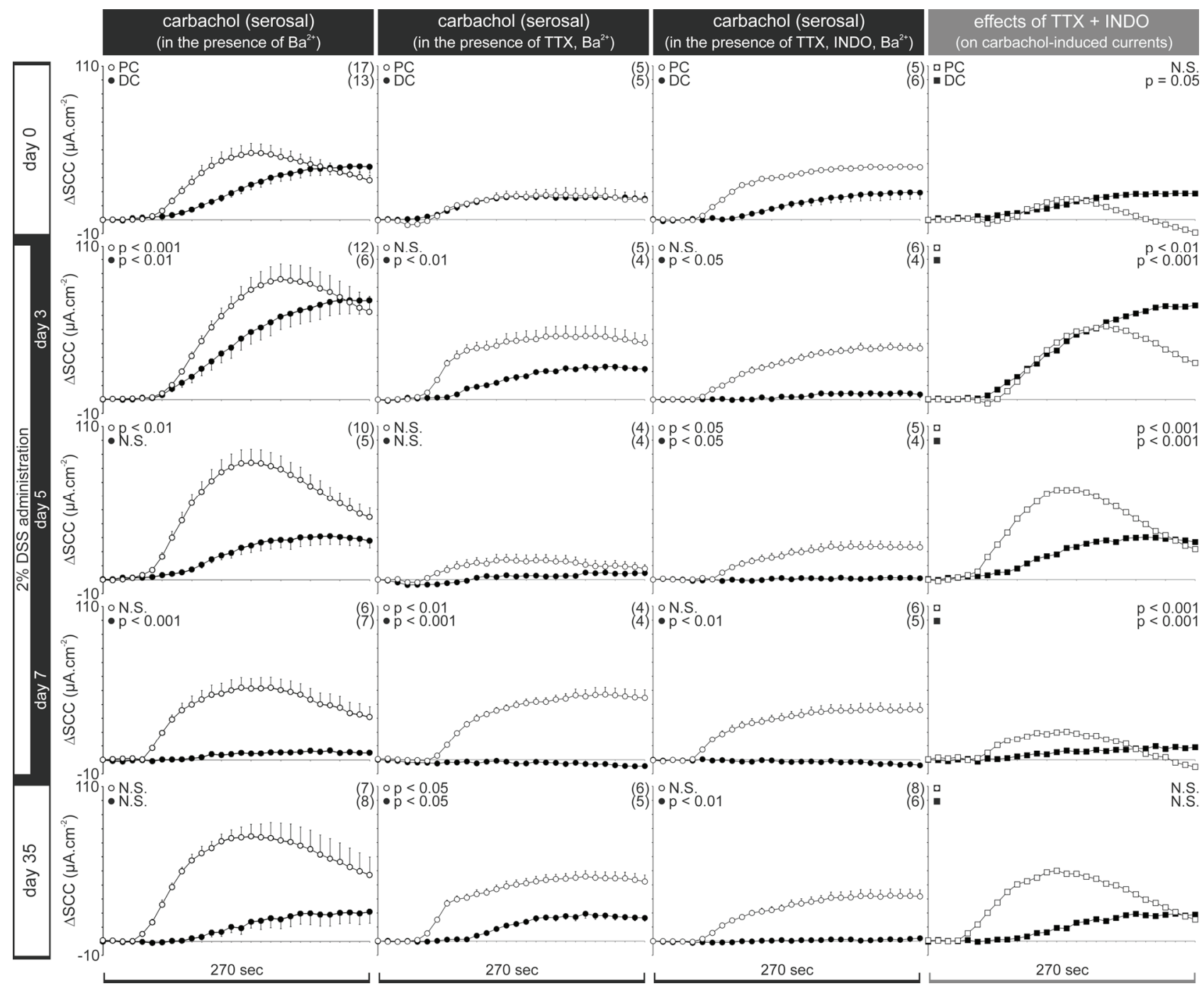

Fig. 4. Effects of enteric nervous system (ENS) and prostaglandins on carbachol-induced current. Mucosal $\mathrm{Ba}^{2+}\left(5.10^{-3} \mathrm{M}\right)$ was used to decrease $\mathrm{K}^{+}$secretion and was applied 5 min before carbachol application in all experiments. Response to carbachol $\left(10^{-4} \mathrm{M}\right)$ alone and in the presence of tetrodotoxin (TTX; $10^{-6} \mathrm{M}$ ) or combination of TTX and indomethacin (INDO; $5.10^{-5}$ ) was measured before (day 0 ), during (day 3, 5 and 7) and 4 weeks after administration of $2 \%$ DSS (day 35) in distal (DC; $\bullet$ ) and proximal colon (PC; $\circ$ ). TTX was used as an inhibitor of ENS and indomethacin inhibited synthesis of COX-derived mediators. The average curve represents 270 sec tracing, but only each $10^{\text {th }}$ point is displayed for simplicity. Combined effect of TTX and indomethacin represents inhibitors-sensitive component of carbachol-induced current. Significant differences between untreated mice (day 0 ) and mice in various stage of colitis or between tissues in the presence or absence of TTX and indomethacin were tested by repeated measures ANOVA. The number of measured animals is in parentheses. 


\section{Carbachol-induced currents during colitis induction}

The response to carbachol was measured in the presence of mucosal $\mathrm{Ba}^{2+}$. It was used to emphasize $\mathrm{Cl}^{-}$ secretion. $\mathrm{K}^{+}$secretion accompanies $\mathrm{Cl}^{-}$secretion and restrains corresponding changes of SCC. A significant difference between carbachol-induced currents in distal and proximal colon was found in untreated mice. The response of distal colon to carbachol was lower and had a shape different from the response of proximal colon $(p<0.001$; Fig. 4). An early and very strong stimulatory effect of DSS on carbachol-induced current was revealed the $3^{\text {rd }}$ day of colitis development in both colonic segments (Fig. 4). In distal colon, the increased responsiveness to carbachol observed the $3^{\text {rd }}$ day of colitis development declined gradually until the $7^{\text {th }}$ day where it was significantly depressed compared to untreated tissue, and returned to the initial level 4 weeks after the DSS insult (Fig. 4). Slightly different course of responsiveness to carbachol was found in proximal colon. Carbachol induced significantly higher response the $3^{\text {rd }}$ and the $5^{\text {th }}$ day of colitis development, but the responsiveness returned to its initial level already the $7^{\text {th }}$ day and remained unchanged 4 weeks after the DSS insult (Fig. 4). Depressed carbachol-induced current was not observed in proximal colon.

\section{Effect of ENS and prostaglandins during colitis development}

In contrast to differences between carbacholinduced currents in the presence of mucosal $\mathrm{Ba}^{2+}$ alone, the addition of TTX eliminated these differences, and carbachol-induced currents in distal and proximal colon were found to be identical in untreated mice. TTX significantly decreased responses to carbachol in both distal $(p<0.01)$ and proximal colon $(p<0.05)$. In comparison to the response in the presence of $\mathrm{Ba}^{2+}$ and TTX, the addition of indomethacin significantly increased response of proximal colon to carbachol $(p<0.05)$. The response of distal colon was not influenced (Fig. 4). During colitis development, TTX reduced the responsiveness to carbachol significantly the $3^{\text {rd }}(p<0.01)$, the $5^{\text {th }}(\mathrm{p}<0.05)$ and the $7^{\text {th }}(\mathrm{p}<0.01)$ day in distal colon and the $3^{\text {rd }}(\mathrm{p}<0.05)$ and the $5^{\text {th }}(\mathrm{p}<0.001)$ day in proximal colon (Fig. 4). The additive inhibitory effect of indomethacin on TTX-resistant carbachol-induced current was observed the $3^{\text {rd }}$ day of colitis development $(p<0.001)$ and 4 weeks after DSS insult $(p<0.001)$ in distal colon, and the $7^{\text {th }} \quad(p<0.05)$ day of colitis development in proximal colon. The combined effect of
TTX and indomethacin on carbachol-induced current in the presence of mucosal $\mathrm{Ba}^{2+}$ is displayed on Figure 4 (last column). It shows the evident increase of inhibitorsensitive component of carbachol-induced current the $3^{\text {rd }}$ day of colitis development in distal colon, and the $3^{\text {rd }}$ and the $5^{\text {th }}$ day in proximal colon.

\section{Potassium channels involvement}

Adding $\mathrm{Ba}^{2+}$ to the mucosal side of both distal and proximal colon caused an increase in SCC that likely corresponded to decreased $\mathrm{K}^{+}$secretion. Significantly different responses of distal and proximal colon were measured in untreated mice $(\mathrm{p}<0.001$; Fig. 5). Although there are some significant differences throughout colitis development, there is not dramatic change of $\mathrm{Ba}^{2+}$ sensitive currents in either size or shape. A different situation was observed after $\mathrm{Ba}^{2+}$ addition to the serosal side of proximal colon during colitis development. Responses to serosal $\mathrm{Ba}^{2+}$ could at least partially reflect baseline ion transport activity, but also certainly reflect activity and/or expression of $\mathrm{K}^{+}$channels on apical and basolateral membrane. Significantly different responses of distal and proximal colon were measured in untreated mice ( $\mathrm{p}<0.001$; Fig. 5). In distal colon, colitis intensified negative response to serosal $\mathrm{Ba}^{2+}$, but only in the $3^{\text {rd }}$ day of colitis development. In the proximal colon, the shape of responses to serosal $\mathrm{Ba}^{2+}$ changed dramatically during colitis development and was significantly different compared to untreated mice on the $3^{\text {rd }}$, the $5^{\text {th }}$ and the $7^{\text {th }}$ day (Fig. 5). These changes were reversible, because 4 weeks after the DSS insult the response to serosal $\mathrm{Ba}^{2+}$ was similar to that of untreated tissue (data not shown).

\section{Discussion}

DSS administration is the most common murine model of experimental colitis with symptoms that mimic ulcerative colitis (Okayasu et al. 1990). In studies, where decreased responsiveness of distal colon to carbachol was found, $4 \%$ DSS was administered for 5 days (DiazGranados et al. 2000, Sayer et al. 2002, Green et al. 2004). We used a lower dose of DSS (2\%) to slow colitis development and to avoid the increased mortality of BALB/c mice we observed in preliminary experiments. Although increased transcription levels of TNF- $\alpha$ and IL$1 \beta$ were observed after DSS treatment also in proximal colon (Azuma et al. 2008, Yan et al. 2009), only the distal or mid-distal colon responses to carbachol were studied (Diaz-Granados et al. 2000, Sayer et al. 2002, 


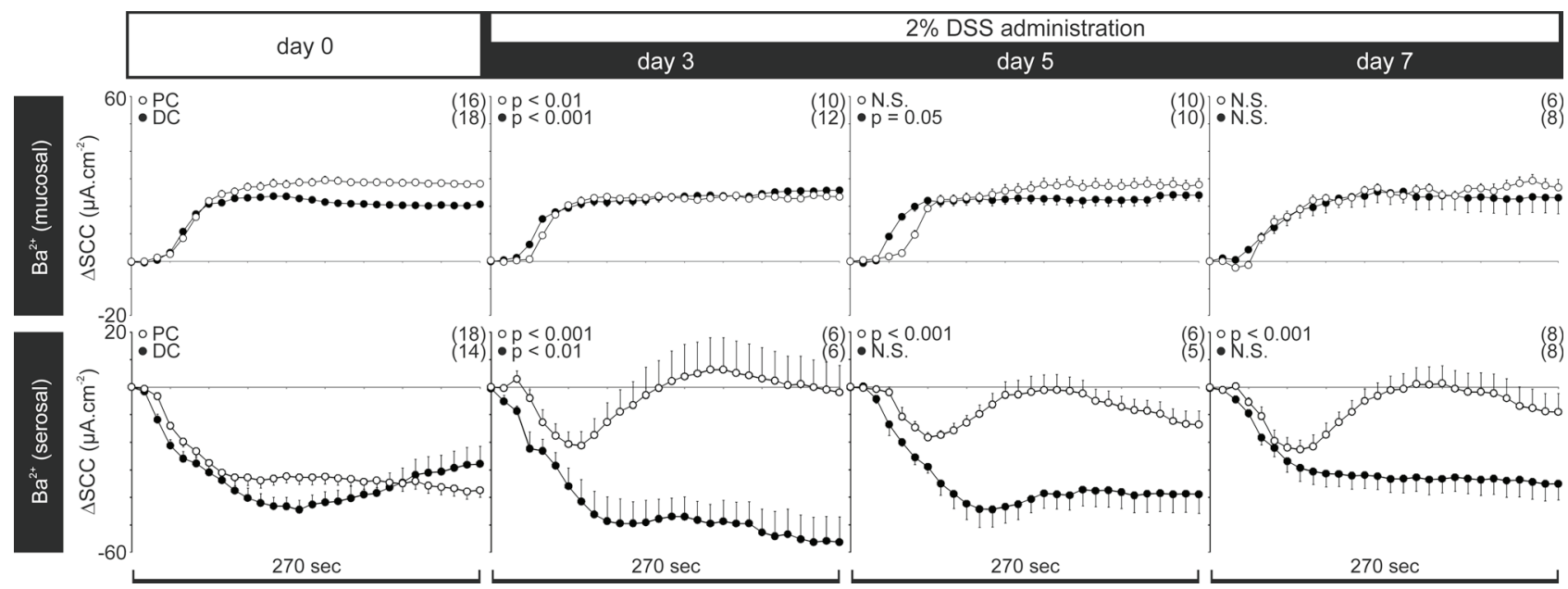

Fig. 5. $\mathrm{Ba}^{2+}$-sensitive currents. $\mathrm{Ba}^{2+}$-sensitive current was measured before (day 0 ), during (day 3,5 and 7 ) and 4 weeks after administration of $2 \%$ DSS (day 35, not shown) in distal (DC; $\bullet$ ) and proximal colon (PC; $\circ$ ). $\mathrm{Ba}^{2+}$ was added to mucosal or serosal side. The average curve represents $270 \mathrm{sec}$ tracing, but only each $10^{\text {th }}$ point is displayed for simplicity. Significant differences between untreated mice (day 0 ) and mice in various stage of colitis were tested by repeated measures ANOVA. The number of measured animals is in parentheses.

Green et al. 2004). Our data confirm increased transcription levels of IL- $1 \beta$, but not TNF- $\alpha$ after 7 days DSS administration in proximal colon. Similarly, an upregulation of COX-2 transcription, but no change of COX-1 transcription was described in distal colon during $3 \%$ (w/v) DSS colitis induction (Tanaka et al. 2008). We have no explanation for our conflicting data concerning COX-1 expression in distal and proximal colon, except the different mice strain (ICR) used by Tanaka et al. (2008). We suggest that infiltration of immune cells could be involved. Nevertheless, as we used the wholethickness segments of colon, we cannot specify the source of measured mRNA. Although the transcription of selected molecular markers of inflammation was significantly increased mainly the $7^{\text {th }}$ day of colitis development, we observed an effect of DSS on carbachol-induced current already on the $3^{\text {rd }}$ day. The early effect of DSS is consistent with the fast DSS effect observed in murine colon by Johansson et al. (2010). They recently demonstrated $53 \%$ reduction of the mucus layer thickness after $15 \mathrm{~min}$ exposure to $3 \%$ DSS. In addition, the inner mucus layer that forms a protective barrier against bacteria and is usually devoid of them, was severely impaired by DSS. Already $12 \mathrm{~h}$ after DSS exposure large number of bacteria penetrated into that layer (by leukocytes infiltration). Finally, bacterial penetration into the submucosa, accompanied by leukocytes infiltration, was observed after 5 days of DSS administration. The early changes in colonic secretion that we observed may be at least in part attributable to enterochromaffin cells. These cells are stimulated by penetrating bacteria and secrete serotonin. There is evidence that serotonin availability increases in experimental colitis in murine distal colon (Bertrand et al. 2010). An important role of serotonin was demonstrated by fluoxetine, a selective serotonin reuptake inhibitor that attenuated the severity of DSS-induced acute colitis in mice (Koh et al. 2011). In our experiments, the reduction of increased responsiveness of distal and proximal colon to carbachol by inhibition of ENS activity and prostaglandins synthesis may occur in conjunction with the secretory effect of serotonin. Serotonin modulates intestinal secretion directly or indirectly via ENS and prostaglandins release (Gershon and Tack 2007). But, unchanged TTX-sensitive and indomethacin-sensitive currents on the $3^{\text {rd }}$ and $5^{\text {th }}$ day of DSS administration may contradict it. Inhibitory effect of indomethacin on TTXsensitive current may be due to the inhibition of direct effect of prostaglandin $\mathrm{E}_{2}$ on VIP non-cholinergic secretomotor neurons of submucosal plexus, an interaction described on guinea pig ileum (Dekkers et al. 1997). Similarly, inhibitory effect of TTX on the $7^{\text {th }}$ day of DSS administration may be related to this effect and becoming visible after an increase in prostaglandins level. We suggest that prostaglandins level was increased because of the complementary effects of augmented cyclooxygenases expression and IL-1 $\beta$ expression. IL-1 $\beta$ was shown to increase prostaglandin $\mathrm{E}_{2}$ level by Bode et al. (1998). The role of ENS and prostaglandins in maintaining responsiveness of colonocytes to carbachol was shown in mice by Carew and Thorn (2000). Besides the early effect of DSS on carbachol-induced current in 
distal and proximal colon, we observed an unchanged response to carbachol after 7 days of DSS administration in proximal colon. It contrasts with depressed carbacholinduced current observed in distal colon also by others (Diaz-Granados et al. 2000, Sayer et al. 2002, Green et al. 2004).

Our findings with $\mathrm{K}^{+}$channels blocker $\mathrm{Ba}^{2+}$ indicate that these channels play a role in intestinal fluid losses in secretory diarrhea. The only $\mathrm{K}^{+}$channel involved in $\mathrm{K}^{+}$secretion seems to be $\mathrm{Ca}^{2+}$ dependent $\mathrm{K}^{+}$ channel $\left(\mathrm{K}_{\mathrm{Ca}} 1.1\right)$ that is expressed on both apical and basolateral membrane of colonocytes in both distal and proximal colon. It is sensitive to $\mathrm{Ba}^{2+}$, tetraethylamonium (TEA) or iberiotoxin (Sandle and Hunter 2010, Sorensen et al. 2010). The involvement of $\mathrm{K}_{\mathrm{Ca}} 1.1$ channel is also suggested by increased expression of the channel found in the inflamed human sigmoid and ascending colon of UC patients (Sandle et al. 2007). However, there are no available data on expression of $\mathrm{K}_{\mathrm{Ca}} 1.1$ or other $\mathrm{K}^{+}$ channels during colitis development that may help explain surprising response of proximal colon to serosal $\mathrm{Ba}^{2+}$ during DSS administration. Hirota and McKay (2009) described unchanged expression of basolateral $\mathrm{K}_{\mathrm{Ca}} 3.1$ channel in colonic crypts at either the mRNA or protein level, but only after DSS insult, not during DSS administration. Sandle and Hunter (2010) formulated hypothesis that prostaglandin $\mathrm{E}_{2}$ could inhibit opening of $\mathrm{K}_{\mathrm{Ca}} 1.1$ channels in the apical membrane through protein kinase A (PKA). It is consistent with our data obtained on untreated mice. Responses of proximal colon to serosal $\mathrm{Ba}^{2+}$ in the presence of mucosal $\mathrm{Ba}^{2+}$ were similar in shape to the responses to serosal $\mathrm{Ba}^{2+}$ during DSS administration (data not shown), but it has to be confirmed by further experiments.

In conclusion, $2 \%$ DSS administration affects not only distal, but also proximal colon. Whereas the cholinergic response of acutely inflamed distal colon decreased, there was not any decrease in responsiveness of proximal colon. In contrast, early induction of colitis significantly stimulated carbachol-induced current in both distal and proximal colon after 3 days of DSS administration. This increased capacity of carbachol to induce SCC changes utilizes both ENS (TTX-sensitive) and prostaglandins pathways. Our study provides new insight into the pathophysiology of DSS model of colitis.

\section{Conflict of Interest}

There is no conflict of interest.

\section{Acknowledgements}

The study was supported by grants from Charles University (GA UK 25410) and Academy of Sciences (AVOZ50110509).

\section{Abreviations}

CFTR, cystic fibrosis transmembrane conductance regulator; COX-1, COX-2, cyclooxygenases type 1, 2; DSS, dextran sodium sulfate; ENaC, epithelial sodium channel; ENS, enteric nervous system; IBD, inflammatory bowel disease; IL-1 $\beta$, interleukin-1 $\beta$; $\mathrm{K}_{\mathrm{Ca}} 1.1, \mathrm{Ca}^{2+}$ dependent $\mathrm{K}^{+}$channel (alternative names BK, KCNMA1); $\mathrm{K}_{\mathrm{Ca}} 3.1, \mathrm{Ca}^{2+}$ dependent $\mathrm{K}^{+}$channel (alternative names IK, KCNN4); $\mathrm{NKCC1}, \quad \mathrm{Na}^{+}-\mathrm{K}^{+}-2 \mathrm{Cl}^{-}$ cotransport isoform 1; SCC, short-circuit current; TNF- $\alpha$, tumor necrosis factor- $\alpha$; TTX, tetrodotoxin; UC, ulcerative colitis; VIP, vasoactive intestinal peptide.

\section{References}

ASFAHA S, BELL CJ, WALLACE JL, MACNAUGHTON WK: Prolonged colonic epithelial hyporesponsiveness after colitis: role of inducible nitric oxide synthase. Am J Physiol 176: G703, 1999.

AZUMA YT, HAGI K, SHINTANI N, KUWAMURA M, NAKAJIMA H, HASHIMOTO H, BABA A, TAKEUCHI T: PACAP provides colonic protection against dextran sodium sulfate induced colitis. $J$ Cell Physiol 216: 111119, 2008.

BARRETT KE, KEELY SJ: Chloride secretion by the intestinal epithelium: molecular basis and regulatory aspects. Annu Rev Physiol 62: 535-572, 2000.

BERTRAND PP, BARAJAS-ESPINOSA A, NESHAT S, BERTRAND RL, LOMAX AE: Analysis of real-time serotonin (5-HT) availability during experimental colitis in mouse. Am J Physiol Gastrointest Liver Physiol 298: G446-G455, 2010.

BODE H, SCHMITZ H, FROMM M, SCHOLZ P, RIECKEN EO, SCHULZKE JD: IL-1beta and TNF-alpha, but not IFN-alpha, IFN-gamma, IL-6 or IL-8, are secretory mediators in human distal colon. Cytokine 10: 457-465, 1998. 
CAREW MA, THORN P: Carbachol-stimulated chloride secretion in mouse colon: evidence of a role for autocrine prostaglandin E2 release. Exp Physiol 85: 67-72, 2000.

DEKKERS JA, KROESE AB, KEENAN CM, MACNAUGHTON WK, SHARKEY KA: Prostaglandin E2 activation of VIP secretomotor neurons in the guinea pig ileum. J Auton Nerv Syst 66: 131-137, 1997.

DIAZ-GRANADOS N, HOWE K, LU J, MCKAY DM: Dextran sulfate sodium-induced colonic histopathology, but not altered epithelial ion transport, is reduced by inhibition of phosphodiesterase activity. Am J Pathol 156: 2169-2177, 2000.

FLORES CA, MELVIN JE, FIGUEROA CD, SEPÚLVEDA FV: Abolition of $\mathrm{Ca}^{2+}$-mediated intestinal anion secretion and increased stool dehydration in mice lacking the intermediate conductance $\mathrm{Ca}^{2+}$-dependent $\mathrm{K}^{+}$channel Kcnn4. J Physiol 583: 705-717, 2007.

GERSHON MD, TACK J: The serotonin signaling system: from basic understanding to drug development for functional GI disorders. Gastroenterology 132: 397-414, 2007.

GRAVAGHI C, LA PERLE KM, OGRODWSKI P, KANG JX, QUIMBY F, LIPKIN M, LAMPRECHT SA: Cox-2 expression, PGE(2) and cytokines production are inhibited by endogenously synthesized n-3 PUFAs in inflamed colon of fat-1 mice. J Nutr Biochem 22: 360-365, 2011.

GREEN CL, HO W, SHARKEY KA, MCKAY DM: Dextran sodium sulfate-induced colitis reveals nicotinic modulation of ion transport via iNOS-derived NO. Am J Physiol Gastrointest Liver Physiol 287: G706-G714, 2004.

HABERBERGER R, SCHULTHEISS G, DIENER M: Epithelial muscarinic M1 receptors contribute to carbacholinduced ion secretion in mouse colon. Eur J Pharmacol 530: 229-233, 2006.

HIROTA CL, MCKAY DM: M3 muscarinic receptor-deficient mice retain bethanechol-mediated intestinal ion transport and are more sensitive to colitis. Can J Physiol Pharmacol 84: 1153-1161, 2006a.

HIROTA CL, MCKAY DM: Cholinergic regulation of epithelial ion transport in the mammalian intestine. $B r J$ Pharmacol 149: 463-479, 2006 b.

HIROTA CL, MCKAY DM: Loss of Ca-mediated ion transport during colitis correlates with reduced ion transport responses to a Ca-activated K channel opener. Br J Pharmacol 156: 1085-1097, 2009.

JOHANSSON ME, GUSTAFSSON JK, SJÖBERG KE, PETERSSON J, HOLM L, SJÖVALL H, HANSSON GC: Bacteria penetrate the inner mucus layer before inflammation in the dextran sulfate colitis model. PLoS One 5: e12238, 2010.

KASER A, ZEISSIG S, BLUMBERG RS: Inflammatory bowel disease. Annu Rev Immunol 28: 573-621, 2010.

KOH SJ, KIM JM, KIM IK, KIM N, JUNG HC, SONG IS, KIM JS: Fluoxetine inhibits NF-\{kappa\}B signaling in intestinal epithelial cells, and ameliorates experimental colitis and colitis-associated colon cancer in mice. Am J Physiol Gastrointest Liver Physiol 301: G9-G19, 2011.

KUNZELMANN K, MALL M: Electrolyte transport in the mammalian colon: mechanisms and implications for disease. Physiol Rev 82: 245-289, 2002.

LINDÉN SK, FLORIN TH, MCGUCKIN MA: Mucin dynamics in intestinal bacterial infection. PLoS One 3: e3952, 2008.

MARTÍNEZ-AUGUSTIN O, ROMERO-CALVO I, SUÁREZ MD, ZARZUELO A, DE MEDINA FS: Molecular bases of impaired water and ion movements in inflammatory bowel diseases. Inflamm Bowel Dis 15: 114-127, 2009.

MATOS JE, SAUSBIER M, BERANEK G, SAUSBIER U, RUTH P, LEIPZIGER J: Role of cholinergic-activated KCa1.1 (BK), KCa3.1 (SK4) and KV7.1 (KCNQ1) channels in mouse colonic Cl- secretion. Acta Physiol (Oxf) 189: 251-258, 2007.

MAUCHLY JW: Significance test for sphericity of a normal n-variate distribution. Ann Math Statist 11: 204-209, 1940.

OKAYASU I, HATAKEYAMA S, YAMADA M, OHKUSA T, INAGAKI Y, NAKAYA R: A novel method in the induction of reliable experimental acute and chronic ulcerative colitis in mice. Gastroenterology 98: 694-702, 1990.

PEREZ-NAVARRO R, BALLESTER I, ZARZUELO A, SANCHE DE MEDINA F: Disturbances in epithelial ionic secretion in different experimental models of colitis. Life Sci 76: 1489, 2005.

SANDLE GI, HUNTER M: Apical potassium (BK) channels and enhanced potassium secretion in human colon. $Q J$ Med 103: 85-89, 2010. 
SANDLE GI, PERRY MD, MATHIALAHAN T, LINLEY JE, ROBINSON P, HUNTER M, MACLENNAN KA: Altered cryptal expression of luminal potassium (BK) channels in ulcerative colitis. J Pathol 212: 66-73, 2007.

SAYER B, LU J, GREEN C, SÖDERHOLM JD, AKHTAR M, MCKAY DM: Dextran sodium sulphate-induced colitis perturbs muscarinic cholinergic control of colonic epithelial ion transport. Br J Pharmacol 135: 1794-1800, 2002.

SORENSEN MV, MATOS JE, PRAETORIUS HA, LEIPZIGER J: Colonic potassium handling. Pflugers Arch 459: 645-656, 2010.

TANAKA K, SUEMASU S, ISHIHARA T, TASAKA Y, ARAI Y, MIZUSHIMA T: Inhibition of both COX-1 and COX-2 and resulting decrease in the level of prostaglandins E2 is responsible for non-steroidal antiinflammatory drug (NSAID)-dependent exacerbation of colitis. Eur J Pharmacol 603: 120-132, 2009.

WESTBROOK AM, SZAKMARY A, SCHIESTL RH: Mechanisms of intestinal inflammation and development of associated cancers: lessons learned from mouse models. Mutat Res 705: 40-59, 2010.

YAN Y, KOLACHALA V, DALMASSO G, NGUYEN H, LAROUI H, SITARAMAN SV, MERLIN D: Temporal and spatial analysis of clinical and molecular parameters in dextran sodium sulfate induced colitis. PLoS One 4: e6073, 2009. 